\title{
MAGNETIC PROPERTIES OF THIN FILMS OF Fe-Cu-R-Si-B ALLOYS WITH R = Nd, Gd, Ho, Y
}

\author{
I. GośCIAŃSKA \\ Institute of Physics, A. Mickiewicz University \\ Matejki 48/49, 60-769 Poznań, Poland \\ H. RatajczaK, M. URbaniak
}

Institute of Molecular Physics, Polish Academy of Sciences

Smoluchowskiego 17/19, 60-179 Poznań, Poland

AND M. KonČ

Department of Experimental Physics, P.J. Safarik University, Košice, Slovakia

Hysteresis loops of thin films of $\mathrm{Fe}_{73.5} \mathrm{Cu}_{1} \mathrm{R}_{3} \mathrm{Si}_{13.5} \mathrm{~B}_{9}(\mathrm{R}=\mathrm{Nd}$, Gd, Ho, Y) alloys were studied by the magnetooptical Faraday method. The films were deposited by flash evaporation technique onto cooled glass substrates. Lanthanides were chosen as substitutes for niobium in the FINEMET type alloys. Coercivity, $H_{c}$, was determined from the easy- and hard-axis hysteresis loops. The as-deposited films containing Gd and Ho are characterized by rather low values of $H_{\mathrm{c}}$ while the films with $\mathrm{Nd}$ and $\mathrm{Y}$ show a high isotropic value of $H_{\mathrm{c}}$. Attempts were made to determine the conditions of the film annealing which would ensure the optimum soft magnetic properties of the films studied.

PACS numbers: 75.70.-i, 68.55.-a

Magnetic properties of novel magnetic materials as well as possibility of their utilization are the subject of great interest of scientists and engineers. E.g. nanocrystalline alloys of the $\mathrm{Fe}_{73.5} \mathrm{Cu}_{1} \mathrm{Nb}_{3} \mathrm{Si}_{13.5} \mathrm{~B}_{9}$ type belong to such materials $[1,2]$. In this paper we present results of a study of magnetic properties of thin films made on the basis of the classical nanocrystalline alloy $\mathrm{Fe}_{73.5} \mathrm{Cu}_{1} \mathrm{R}_{3} \mathrm{Si}_{13.5} \mathrm{~B}_{9}$, in which $\mathrm{Nb}$ has been replaced by rare-earth elements $\mathrm{R}$. The lanthanides $\mathrm{R}=$ $\mathrm{Nd}, \mathrm{Gd}$, Ho and $\mathrm{Y}$ (non-lanthanide) were chosen as substitutes in the FINEMET type alloys to test whether they generate nuclei of various magnetic structures [3] and what differences in the magnetic properties they introduce.

The films were prepared by flash evaporation technique and deposition in an ultrahigh vacuum onto glass substrates cooled with liquid nitrogen [4]. The initial material for evaporation was a pulverized alloy with the nominal composition $\mathrm{Fe}_{73.5} \mathrm{Cu}_{1} \mathrm{R}_{3} \mathrm{Si}_{13.5} \mathrm{~B}_{9}$. The films obtained were of 20 to $50 \mathrm{~nm}$ in thickness. 
In order to determine the temperatures at which the structural changes occur, the temperature dependences of electrical resistivity $\rho(T)$ were analysed. The temperature increased at a rate of about $10 \mathrm{~K} / \mathrm{min}$. The samples studied were annealed at temperatures at which changes in their structure were observed.

The resistivity $\rho(T)$ was analysed for the films covered with the protective $\mathrm{SiO}$ films and without that protection.

Hysteresis loops of the films obtained were studied by magnetooptical Faraday method and the coercive field, $H_{\mathrm{c}}$, was determined.

Analysis of the $\rho(T)$ dependences (Fig. 1) obtained for films of all the alloys studied reveals two characteristic types of courses. The first one suggests structural changes of the relaxation type in the low-temperature range, down to about $623 \mathrm{~K}$ and changes related to crystallization above $700 \mathrm{~K}$ (Fig. 1a). The curves of the
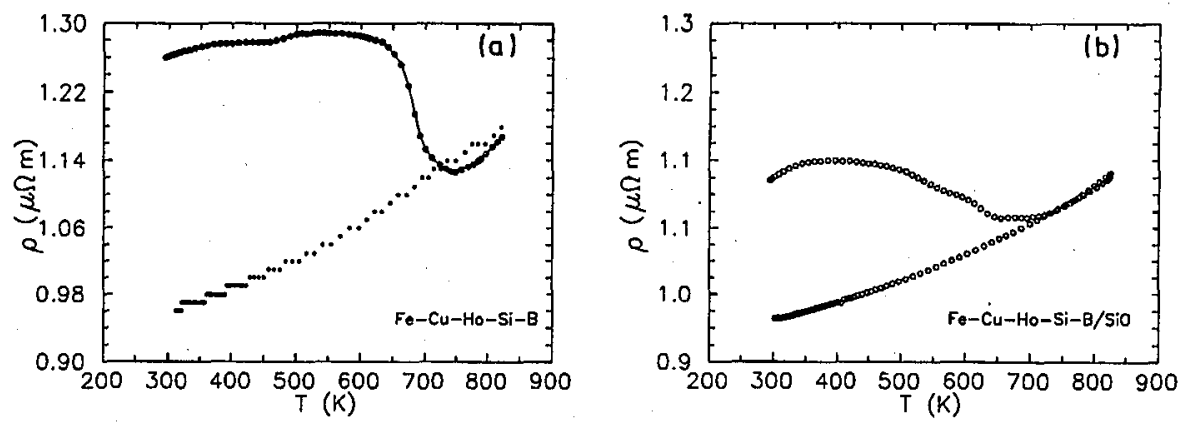

Fig. 1. Two exemplary $\rho(T)$ dependences in the films of $\mathrm{Fe}-\mathrm{Cu}-\mathrm{Ho}-\mathrm{Si}-\mathrm{B}$ for a sample (a) not covered with $\mathrm{SiO}$ layer; and (b) covered with the $\mathrm{SiO}$ protective layer.
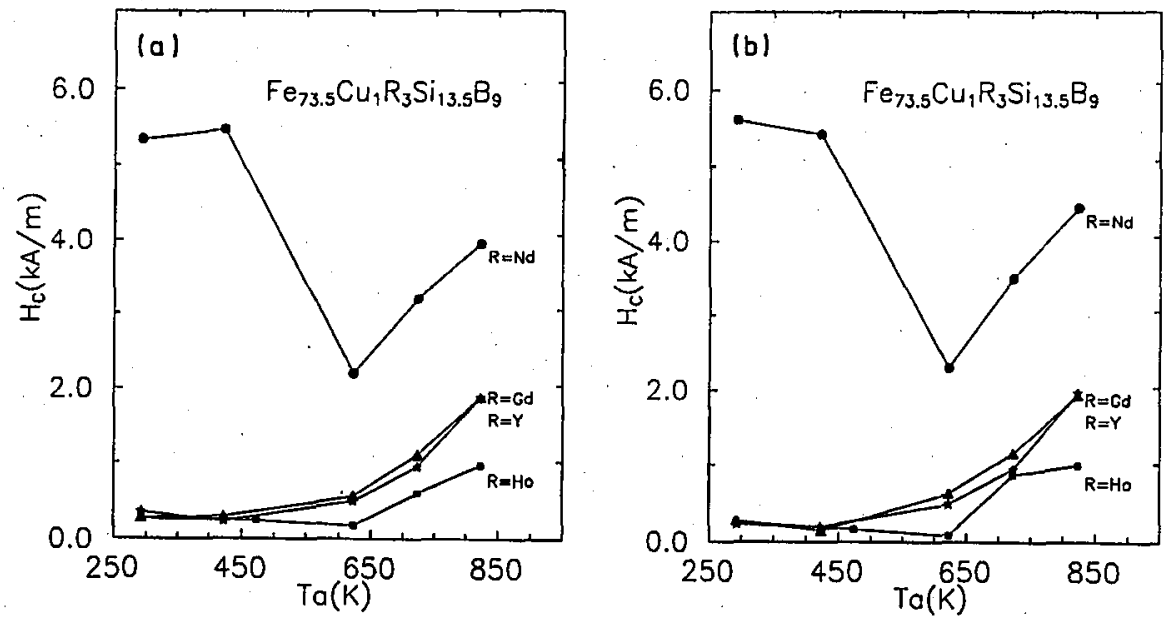

Fig. 2. $H_{\mathrm{c}}^{\|}(\mathrm{a})$ and $H_{\mathrm{c}}^{\perp}$ (b) vs. $T_{a}$ for the films of $\mathrm{Fe}-\mathrm{Cu}-\mathrm{R}-\mathrm{Si}-\mathrm{B}(\mathrm{R}=\mathrm{Nd}, \mathrm{Gd}$, Ho, Y). 
latter type indicate only the occurrence of the crystallization transition (Fig. 1b). Accordingly, it can be concluded that the films characterized by the former type of $\rho(T)$ dependence are amorphous as-deposited while those characterized by the latter type of $\rho(T)$ have already partly relaxed on evaporation of the protective $\mathrm{SiO}$ film. This effect does not depend on the kind of alloy but rather on their thermal treatment. For as-deposited amorphous films, the temperature of crystallization, $T_{x}$, can be relatively accurately estimated to be of about $673 \mathrm{~K}$ for all films studied. Such a low value of $T_{x}$ makes highly unlikely the occurrence of the nanocrystalline structure.

Hysteresis loops and temperature dependences of $H_{\mathrm{c}}$ were measured for the films not covered with a film of SiO. Figure 2 presents the temperature dependences of coercive field for the as-deposited films annealed for 10 minutes at the structure relaxing temperatures $T_{a 1}=423 \mathrm{~K}, T_{a 2}=623 \mathrm{~K}$, and at temperatures higher than the crystallization temperature: $T_{a 3}=723 \mathrm{~K}, T_{a 4}=823 \mathrm{~K}$. A general character of the dependences of $H_{\mathrm{c}}^{\| l}$ (Fig. 2a) and $H_{\mathrm{c}}^{\perp}$ (Fig. 2b) on the annealing temperature $T_{a}$ is the same, at first $H_{c}$ decreases and increases after crystallization. However, a detailed analysis of $H_{c} \|\left(T_{a}\right)$ reveals that the value of $H_{c}$ is largely affected by the magnetic structure of crystal nuclei which is sperimagnetic in $\mathrm{Nd}-\mathrm{Fe}$, ferrimagnetic in $\mathrm{Gd}-\mathrm{Fe}$ and $\mathrm{Ho}-\mathrm{Fe}$ and asperomagnetic in $\mathrm{Y}-\mathrm{Fe}$. The as-deposited $\mathrm{Fe}-\mathrm{Cu}-\mathrm{Nd}-\mathrm{Si}-\mathrm{B}$ films are characterized by high $H_{\mathrm{c}}>5 \mathrm{kA} / \mathrm{m}$ and isotropic in-plane magnetization. The value of their $H_{\mathrm{c}}$ decreases with growing $T_{a}$ and increases after crystallization point. For $\mathrm{Fe}-\mathrm{Cu}-\mathrm{Ho}-\mathrm{Si}-\mathrm{B}$ films the coercive field $H_{c}^{\|}$changes from $0.27 \mathrm{kA} / \mathrm{m}$ for as-deposited state to $0.18 \mathrm{kA} / \mathrm{m}$ after annealing at $623 \mathrm{~K}$ and subsequently increases to $0.97 \mathrm{kA} / \mathrm{m}$ after annealing at $T_{a 4}=823 \mathrm{~K}$ (Fig. 2). The $H_{\mathrm{c}}$ values obtained for $\mathrm{Fe}-\mathrm{Cu}-\mathrm{Gd}-\mathrm{Si}-\mathrm{B}$ are similar to those of the alloy containing Ho. The films of the alloy containing Y (Fig. 3) have

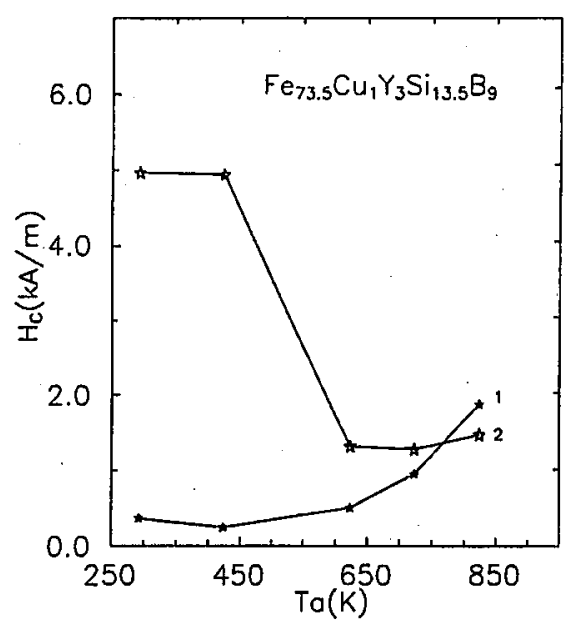

Fig. 3. $H_{c}^{\|}$vs. $T_{a}$ for the films of $\mathrm{Fe}-\mathrm{Cu}-\mathrm{Y}-\mathrm{Si}-\mathrm{B}$; (1) not covered with $\mathrm{SiO},(2)$ covered with $\mathrm{SiO}$ protective layers. 
their $H_{c}^{\|}$values very sensitive to the conditions of thermal treatment and changing from 0.36 to $5 \mathrm{kA} / \mathrm{m}$.

Two types of temperature dependence of resistivity $\rho(T)$, depending on the amount of the amorphous phase, were observed for the films studied. The values of the coercive field of the films were found to depend on the type of magnetic structure of crystalline clusters. The highest values: $H_{c}>5 \mathrm{kA} / \mathrm{m}$, were measured for $\mathrm{Nd}-\mathrm{Fe}$ of sperimagnetic structure and $\mathrm{Y}-\mathrm{Fe}$ of asperomagnetic structure. Films of the alloys containing $\mathrm{Gd}$ and Ho were characterized by low $H_{\mathrm{c}}$ values as expected of the ferrimagnetic $\mathrm{Gd}-\mathrm{Fe}$ and $\mathrm{Ho}-\mathrm{Fe}$.

We shall continue the studies on a larger range of lanthanides in order to confirm our conclusions.

\section{References}

[1] Y. Yoshizawa, S. Oguma, K. Yamauchi, J. Appl. Phys. 64, 6044 (1988).

[2] G. Herzer, IEEE Trans. Magn. 25, 3327 (1989); 26, 1397 (1990).

[3] J.M.D. Coey, J. Appl. Phys. 49, 1646 (1978).

[4] H. Ratajczak, I. Gościańska, P. Sovák, M. Konč, P. Matta, Phys. Status Solidi A 136, 119 (1993). 